\title{
“Agricon”-Weather Monitoring System and Irrigation Controller
}

\author{
Pranita Bhosale ${ }^{1}$, V.V.Dixit ${ }^{2}$ \\ ${ }^{1,2}$ (Electronics and Telecommunication, SCOE, Pune, India)
}

\begin{abstract}
For weather monitoring system and irrigation controller, we need to measure different parameters i.e. Atmospheric temperature, Humidity, Wind speed, Wind direction, Radiation, Soil temperature, Sunshine and Rain fall etc. The key objective of this project is to report on a developed indigenous low cost time based microcontroller based irrigation scheduler who performs user defined functions and outputs commands to derive appropriate actuators (relay, solenoid valves, motor). A soil moisture sensor was modeled, simulated and tested for achieving, with low-cost, accurate and reliable measurements. A low-cost high-performance and small temperature sensor is used, with the same PCB circuit it can measure humidity also. The tipping bucket rain gauge is used to measure rain fall. After a pre-set amount of precipitation falls, the lever tips, dumping the collected water and sending an electrical signal. An anemometer is a device used for measuring wind speed, and is a common weather station instrument. Hence current research focuses on precision agriculture, soil conservation and crop irrigation scheduling and water quantity control for increasing water use efficiency. There is a need to develop new indigenous irrigation controller to improve farm productivity and input use efficiency of water and other nutrients. This system presents the design and development of Irrigation controller System built around PIC16F877A microcontroller. The system consists of microcontroller, peripherals including RTC, LCD and driver circuit relay to switch on/off a motor.
\end{abstract}

Keywords - Anemometer, irrigation controller, irrigation scheduler, tipping bucket rain gauge, weather monitoring

\section{Introduction}

A weather station is a facility, either on land or sea, with instruments and equipment for observing atmospheric conditions to provide information for weather forecasts and to study the weather and climate. The measurements taken include temperature, barometric pressure, humidity, wind speed, wind direction, and precipitation amounts. Wind measurements are taken as free of other obstructions as possible, while temperature and humidity measurements are kept free from direct solar radiation. Manual observations are taken at least once daily, while automated observations are taken at least once an hour. Weather conditions out at sea are taken by ships and buoys, which measure slightly different meteorological quantities such as sea surface temperature, wave height, and wave period. Drifting weather buoys outnumber their moored versions by a significant amount.

Water is a basic component of all known life on Earth. Water can both sustain life in correct quantities and threaten life when it is not available. Water as a result is a very precious natural resource that must not be wasted. If too much water is applied the problems arise consisting of runoff, erosion, waste of water and deceased plant life. If too little water is applied different problems arise such as turf burnout. The key in irrigation is striking to correct balance for optimal plant life with optimal use of water. An irrigation controller is a device to operate automatic irrigation systems such as lawn sprinklers and drip irrigation systems. Most controllers have a means of setting the frequency of irrigation, the start time, and the duration of watering. Some controllers have additional features such as multiple programs to allow different watering frequencies for different types of plants, rain delay settings, input terminals for sensors such as rain and freeze sensors, soil moisture sensors, weather data, remote operation, etc.

Soil moisture sensor is a sensor connected to an irrigation system controller that measure soil moisture content in the active root zone. When connected to conventional system irrigation time clocks, soil moisture sensors can override scheduled watering events by interrupting the irrigation controller circuit when adequate moisture is detected in the soil. The sensors have user-adjustable moisture content set-points that allow unique watering regimes based on plant species, soil type, and/or seasonal rainfall. The anemometer measures wind direction and speed. The anemometer arm comes partially assembled with the wind vane attached. The wind vane rotates $360^{\circ}$ to display current and dominant wind directions on the compass rose of the console display. The rain collector tipping bucket mechanism contains a standard measurement weight magnet that takes measurements in 0.01" (US versions) or $0.2 \mathrm{~mm}$ (UK and EU versions). Rain enters the collector cone, passes through a debris-filtering screen, and collects in one chamber of the tipping bucket. The bucket tips when it has collected an amount of water equal to the increment in which the collector measures 0.01 " or $0.2 \mathrm{~mm}$. As the bucket tips, it causes a switch closure and brings the second tipping bucket chamber into position. The rain water drains out through the screened drains in the base of the collector. The Solar Radiation Sensor, or solar pyranometer, measures global radiation, the sum at the point of measurement of both the direct and diffuse 
components of solar irradiance. The sensor's transducer, which converts incident radiation to electrical current, is a silicon photodiode with wide spectral response. From the sensor's output voltage, the console calculates and displays solar irradiance. Sensirion's family of surface mountable relative humidity and temperature sensors. The sensors integrate sensor elements plus signal processing on a tiny foot print and provide a fully calibrated digital output. A unique capacitive sensor element is used for measuring relative humidity while temperature is measured by a band-gap sensor.

\subsection{Project undertaken}

The health of a plant is influenced by many factors. Weather monitoring system will measure various parameters like wind speed and direction, rain fall, radiation, temperature and humidity etc. One of the most important is being the ready availability of moisture in the soil. Irrigation without soil moisture monitoring is like driving a car without a speedometer - but with the potential for much greater penalties. Monitoring tells us more than when and how much to irrigate, it helps improve the bottom line experience has proven that manipulating moisture levels allows a grower to influence the balance between canopy size and fruitfulness, to manage stress, to maximize growth days and increase control over fruit yield and quality - thereby improving farm revenue.

\subsection{Need for weather monitoring system}

Weather monitoring is the monitoring and analyzing of data that are received at a distance from their source. Monitoring the weather conditions manually is difficult. This is the implementation of an automated system which monitors the weather conditions like temperature, humidity, rainfall, wind speed, radiation and sends the details through the SMS to a central station.

Benefits of weather monitoring system

- Reliable \& efficient data offload, storage \& display

- High quality equipment built to specification

- Flexible service \& installation options

- Portability

\subsection{Organization of the project}

The dissertation work was carried out at Vasantdada Sugar Institute, manjari. The scope of the project can be is discussed as below:

1. Study of need for monitoring:

- Embedded systems

- Need for monitoring

2. Design and development of the monitoring system:

- Study of the present system

- Scope and need of monitoring in the system.

- To replace expensive system by low cost \& reliable system.

It is important that measurements are made regularly and recorded systematically to allow improvement in irrigation scheduling and soil/plant management decisions. The need to determine the moisture status of the soil is a critical factor influencing plant production. Moisture content of the soil is a major factor determining plant's growth, especially in irrigated systems.

The basic objective of irrigation scheduling is to minimize water stress of the plant, that of over irrigation, and under irrigation. The basic requirement is the ability to regularly obtain objective data. The ability to accurately measure soil water content, plant size and condition is an integral mechanism in the process of developing an irrigation scheduling program that allows a better understanding of plant and soil water relations The objective of present work is to get an efficient weather monitoring system. Here efficient system which reliable in any situation and consistent in data transmission. To achieve this objective, GSM modem- SIM300 as a transmitting media is chosen. 


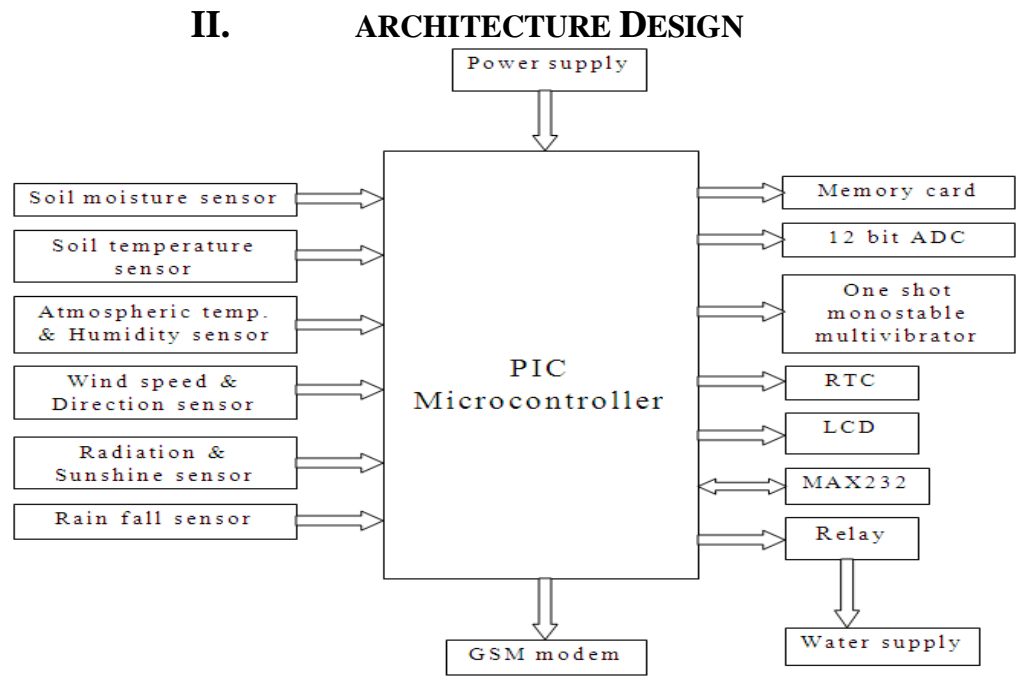

Figure 2.1 System Block Diagram

\subsection{The input parameters that are used by the system are}

\subsubsection{Atmospheric temperature and humidity}

SHT1x (including SHT10, SHT11 and SHT15) is Sensirion's family of surface mountable relative humidity and temperature sensors. The sensors integrate sensor elements plus signal processing on a tiny foot print and provide a fully calibrated digital output. A unique capacitive sensor element is used for measuring relative humidity while temperature is measured by a band-gap sensor. The applied technology guarantees excellent reliability and long term stability. Both sensors are seamlessly coupled to a 14bit analog to digital converter and a serial interface circuit. This results in superior signal quality, a fast response time and insensitivity to external disturbances (EMC).

Humidity is a term for the amount of water vapour in the air, and can refer to any one of several. Formally, humid air is not "moist air" but a mixture of water vapour and other constituents of air, and humidity is defined in terms of the water content of this mixture, called the Absolute humidity .Specific humidity is a ratio of the water vapor content of the mixture to the total air content (on a mass basis).

\subsubsection{Soil Temperature}

It is a measure of temperature at different levels of the Earth's atmosphere. It is governed by many factors, including incoming solar radiation, humidity and altitude. This variable should be defined as a continuous signal (normally as a sine wave which simulated the day and night temperature changes) [2].

An analog temperature sensor that is LM35 is a chip that tells us what the ambient temperature is. These sensors use a solid-state technique to determine the temperature. That is to say, they don't use mercury (like old thermometers), bimetallic strips (like in some home thermometers or stoves), nor do they use thermistors (temperature sensitive resistors). Instead, they use the fact as temperature increases, the voltage across a diode increases at a known rate. Technically, this is actually the voltage drop between the base and emitter of a transistor. By precisely amplifying the voltage change, it is easy to generate an analog signal that is directly proportional to temperature. These sensors have no moving parts, they are precise, never wear out, don't need calibration, work under many environmental conditions, and are consistent between sensors and readings. Moreover they are very inexpensive and quite easy to use.

The LM35 series are precision integrated-circuit temperature sensors, whose output voltage is linearly proportional to the Celsius (Centigrade) temperature. The LM35 thus has an advantage over linear temperature sensors calibrated in ${ }^{\circ}$ Kelvin, as the user is not required to subtract a large constant voltage from its output to obtain convenient Centigrade scaling. The LM35 does not require any external calibration or trimming to provide typical accuracies of $\pm 1 / 4^{\circ} \mathrm{C}$ at room temperature and $\pm 3 / 4^{\circ} \mathrm{C}$ over a full -55 to $+150^{\circ} \mathrm{C}$ temperature range. Low cost is assured by trimming and calibration at the wafer level. The LM35's low output impedance, linear output, and precise inherent calibration make interfacing to readout or control circuitry especially easy. It can be used with single power supplies, or with plus and minus supplies. As it draws only $60 \mu \mathrm{A}$ from its supply, it has very low self-heating, less than $0.1^{\circ} \mathrm{C}$ in still air. The LM35 is rated to operate over a $-55^{\circ}$ to $+150^{\circ} \mathrm{C}$ temperature range, while the $\mathrm{LM} 35 \mathrm{C}$ is rated for a $-40^{\circ}$ to $+110^{\circ} \mathrm{C}$ range.

\subsubsection{Radiation and sunshine}

The Solar Radiation Sensor, or solar pyranometer, measures global radiation, the sum at the point of measurement of both the direct and diffuse components of solar irradiance. The sensor's transducer, which 
converts incident radiation to electrical current, is a silicon photodiode with wide spectral response. From the sensor's output voltage, the console calculates and displays solar irradiance. It also integrates the irradiance values and displays total incident energy over a set period of time. The outer shell shields the sensor body from thermal radiation and provides an airflow path for convection cooling of the body, minimizing heating of the sensor interior. It includes a cutoff ring for cosine response, a level indicator, and fins to aid in aligning the sensor with the sun's rays. The space between the shield and the body also provides a runoff path for water, greatly reducing the possibility of rain- or irrigation-water entrapment. The diffuser is welded to the body for a weather-tight seal; it provides an excellent cosine response. The transducer is an hermetically-sealed silicon photodiode with integrated amplifier. Spring-loaded mounting screws, in conjunction with the level indicator, enable rapid and accurate leveling of the sensor. Each sensor is calibrated against a secondary standard Pyranometer in natural daylight. Sunshine duration is the length of time that the ground surface is irradiated by direct solar radiation (i.e. sunlight reaching the earth's surface directly from the sun). In 2003, WMO defined sunshine duration as the period during which direct solar irradiance exceeds a threshold value of 120 watts per square meter $(\mathrm{W} / \mathrm{m} 2)$. This value is equivalent to the level of solar irradiance shortly after sunrise or shortly before sunset in cloud-free conditions.

\subsubsection{Soil moisture}

The health of a plant is influenced by many factors, one of the most important being the ready availability of moisture in the soil. Soil moisture is an important component in the atmospheric water cycle, both on a small agricultural scale and in large-scale modelling of land/ atmosphere interaction. Vegetation and crops always depend more on the moisture available at root level than on precipitation occurrence. Water budgeting for irrigation planning, as well as the actual scheduling.

The gypsum block is used to measure soil moisture. The electrical resistance between electrodes embedded in a porous medium (block) is proportional to its water content, which is related to the soil water metric potential of the surrounding soil. Thus, the wetter a block is, the lower the resistance measured across two embedded electrodes.

A gypsum block sensor constitutes an electrochemical cell with a saturated solution of calcium sulfate as electrolyte. The resistance between the block-embedded electrodes is determined by applying a small AC voltage (to prevent block polarization) using a Wheatstone bridge. Since changes to the soil electrical conductivity would affect readings, gypsum is used as a buffer against soil salinity changes (up to a certain level). The inherent problem is that the block dissolves and degrades over time (especially in saline soils) losing its calibration properties. It is recommended that the block pore size distribution match the soil texture being used. The readings are temperature dependent (up to $3 \%$ change $/{ }^{\circ} \mathrm{C}$ ) and field measured resistance should be corrected for differences between calibration and field temperatures. Some reading devices contain manual or self-compensating features for temperature or the manufacture provides correction charts or equations. Its size is up to 4 inch measurement cylinder radius. No maintenance needed for gypsum block. It is simple and inexpensive.

In the control stage desires soil moisture is compared with the measured soil moisture following the comparison, a dynamic decision is made regarding the amount of water to be added to the soil of irrigation action, requires local soil moisture information.

The control stage: The control stage interfaces the desired soil moisture and the measured soil moisture (from the "soil" stage). This stage is intended to keep the actual soil moisture as close as possible to the desired moisture. Its output is the valve control value, which represents the amount of water that should be added to the soil continuously in order to maintain a minimal deviation.

\subsubsection{Wind speed and direction}

Air Speed is the speed of an aircraft relative to the air. Among the common conventions for qualifying airspeed are: indicated airspeed ("IAS"), calibrated airspeed ("CAS"), true airspeed ("TAS"), equivalent airspeed ("EAS") and density airspeed [3].

The anemometer measures wind direction and speed. The anemometer arm comes partially assembled with the wind vane attached. The anemometer comes with a 40' $(12 \mathrm{~m})$ cable for flexibility in configuring the system to monitor wind conditions. For example, the anemometer could be mounted at the highest point of a roof.

The wind vane rotates $360^{\circ}$ to display current and dominant wind directions on the compass rose of the console display. To obtain accurate readings, the vane must be correctly oriented when mounting the anemometer outside. By default, the wind vane reports the correct wind direction if the anemometer arm points true north. 


\subsubsection{Rain fall}

The rain collector tipping bucket mechanism contains a standard measurement weight magnet that takes measurements in 0.01 " (US versions) or $0.2 \mathrm{~mm}$ (UK and EU versions).

The Rain Collector is designed to meet the guidelines of the World Meteorological Organization. Rain enters the collector cone, passes through a debris-filtering screen, and collects in one chamber of the tipping bucket. The bucket tips when it has collected an amount of water equal to the increment in which the collector measures $0.01 "$ or $0.2 \mathrm{~mm}$. As the bucket tips, it causes a switch closure and brings the second tipping bucket chamber into position. The rain water drains out through the screened drains in the base of the collector. The collector is designed for years of accurate, trouble-free service. The body and base of the collector are constructed of tough, UV resistant plastic; the tipping bucket pivots on bearings that minimize friction and wear. Stainless steel adjustment screws under each chamber of the tipping bucket allow you to fine-tune the calibration of the Rain Collector. Rain Collector is wind tunnel tested to be stable in winds up to $140 \mathrm{MPH}$.

Rainfall intensity is classified according to the rate of precipitation

- Light rain: when the precipitation rate is $<2.5 \mathrm{~mm}$ per hour

- Moderate rain: when the precipitation rate is between $2.5 \mathrm{~mm}-7.6 \mathrm{~mm}$

- Heavy rain: when the precipitation rate is $>7.6 \mathrm{~mm}$ per hour, or between $10 \mathrm{~mm}$ and $50 \mathrm{~mm}$ per hour

- Violent rain: when the precipitation rate is $>50 \mathrm{~mm}$ per hour [4]

\subsection{PIC Microcontroller}

This stage converts the water flow rate, temperature, air humidity, wind speed and light intensity to the actual well balanced readings. The microcontroller accepts data from sensors and compares data with the set points, corresponding signal is generated. According to this, the relay can switch on and off. Simultaneously it sends all sensor data from SIM300 to mobile user at control station. When we want to read data of all the sensors monthly/yearly we can access that data from external memory card storage.

\subsection{The output parameters are}

\section{- GSM modem:}

Short Message Service is GSM techniques to transfer data from distant places such as from one area to the area of the same city or from another city. In our project we are using SMS technique to instant or quick transfer of data or notice to the required destination. It is a convenient facility of the GSM network. A message consisting of a maximum of 160 alphanumeric characters can be send to or from a mobile station. If the subscriber's mobile unit is powered of $f$ or has left the coverage area, the message is stored and offered back to the subscriber when the mobile is powered on or has reentered the coverage area of the network. This function ensures that the message will be received.

In our project we are using SIM300 for transfer of data from weather station. Interfacing with PIC is done with RS-232 through D-TYPE 9 pin connector. SIS is the leading manufacturers of GSM modems for lower price in India.

\section{- $\quad$ Memory card storage:}

In our project we have used memory card. It accepts incoming serial data and then logs data to text files. The files stored in micro SD card can be accessed on PC with the use of external low cost card reader. LED indicates if the logger is connected to card. The switch can be used to start or stop logging action. Accepts any micro SD memory card from $8 \mathrm{MB}$ to $32 \mathrm{~GB}$. These memory cards are available at very low cost due to wide use in mobile phones.

- $\quad$ Opening/closing the valve/switch for water

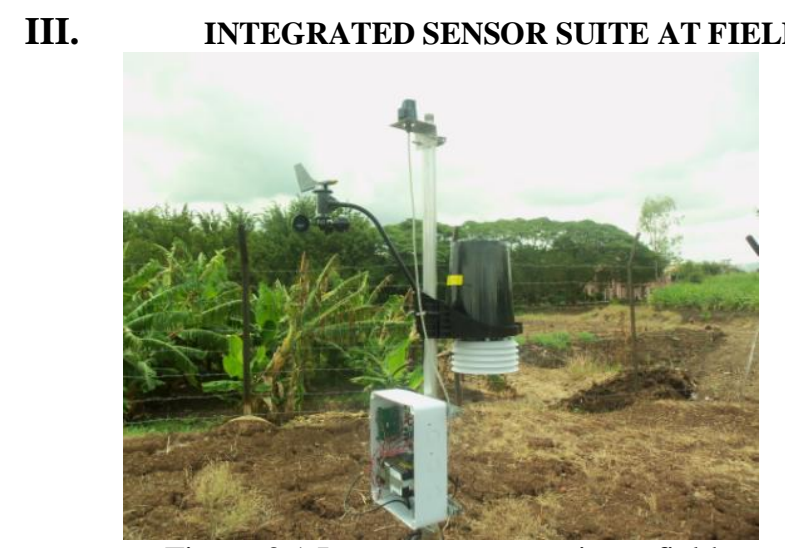

Figure 3.1 Integrate sensor suite at field 
The Integrated Sensor Suite (ISS) collects outside weather data and sends the data to a Weather control station. The standard version of the ISS contains a rain collector, temperature sensor, humidity sensor and anemometer. In addition to the standard weather features, the ISS Plus adds a pre-installed solar radiation sensor and an ultra-violet (UV) radiation sensor. Temperature and humidity sensors are mounted in a passive radiation shield to minimize the impact of solar radiation on sensor readings. The anemometer measures wind speed and direction and can be installed adjacent to the ISS or apart from it. On an ISS Plus, the additional solar and UV sensors are mounted next to the rain collector cone. Separate solar and UV sensors are available to upgrade a standard ISS.

\section{TESTING}

Testing is an integral part of any project work. This is important to check whether the paper design is practically realizable or not. It also realizes the feasibility of the hardware with the design software. The various test cases were designed for the program modules so as to find the errors in the program and an attempt was made o make it error free.

\subsection{Steps done during testing phase}

Following are the test cases that were performed during the testing phase of the project.

1. Verification of PCB layout

a. Tracking of layout.

b. Checking of continuity between the tracks.

2. Circuit testing.

a. Checking for dry solder.

b. Testing output of power supply.

c. Checking of availability of supply at various points on $\mathrm{PCB}$

d. Testing of IC's on IC testers.

e. Software testing for LCD, keyboard, relays using micro controller

3. After completion of PCB testing, the power supply board testing is done.

4. Then power supply from $12 \mathrm{~V}$ battery is connected to main board and specific pin of IC are checked for supply and ground. It is found OK, if sometimes power supply at particular place is not found then the track is checked for discontinuity. Same procedure is applied for other pins for connectivity of other IC's.

5. The IC's are mounted on PCB's and rechecked for supplies and also check the temperature of IC's.

6. For microcontroller we have checked the reset pin, voltage on crystal and output pin ports. The crystal voltages are found OK i.e. 1.5 and 0.5 which indicates that microcontroller is working properly.

7. LCD is also checked so that its screen is also getting ON. Before downloading the software all pins are connected and are checked with multi-meter from starting point to end point.

The proposed work will follow procedure:

\section{RESULT}

All Sensors will determine the moisture level and Radiation, Humidity, Temperature, Wind speed and Rain fall at the root zone. Micro controller should get sensor data per minute. Micro controller should analyze the data, take correct action and record the data.

Soil moisture sensor is a sensor connected to an irrigation system controller that measure soil moisture content in the active root zone before each scheduled irrigation event and bypasses the cycle if soil moisture is above user defined set point. Soil moisture sensors, like rain sensors, are considered rain shut off devices, but while rain sensors measure evapotranspiration rates, soil moisture sensor measures real time moisture.

When connected to conventional system irrigation time clocks, soil moisture sensors can override scheduled watering events by interrupting the irrigation controller circuit when adequate moisture is detected in the soil. The sensors have user-adjustable moisture content set-points that allow unique watering regimes based on plant species, soil type, and/or seasonal rainfall. Micro controller should upload the data once every 24 hours at 8.30am with central server using GSM modem SIM300 to send SMS from weather station to control station.

Once the irrigation starts, Micro controller will request data from corresponding sensor every 30 seconds. When threshold moisture level is reached, it will record the data and stop the irrigation. Stored data will be sent to central server using GSM modem. Similarly reference user defined data table needs to be synchronized after data is uploaded with the server. This will enable user to take out maximum/minimum parameter values from sensors and have them updated at control station. 
$5.1 \quad$ Experimental setup

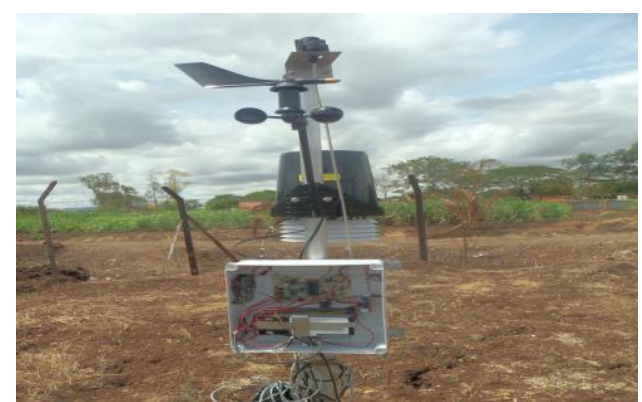

Figure 6.1 Experimental setup at field

Table 6.1 Data recorded at field

\begin{tabular}{|c|c|c|c|c|c|c|c|c|}
\hline $\begin{array}{c}\text { Date } \\
\text { (\$.30am) }\end{array}$ & $\begin{array}{c}\text { Atmospheric } \\
\text { temperature } \\
\left({ }^{\circ} \mathrm{C}\right)\end{array}$ & $\begin{array}{c}\text { Atmospheric } \\
\text { Humidity } \\
(\%)\end{array}$ & $\begin{array}{c}\text { Rainfall } \\
(\mathrm{mm})\end{array}$ & $\begin{array}{c}\text { Wind } \\
\text { speed } \\
(\mathrm{Km} / \mathrm{hr})\end{array}$ & $\begin{array}{c}\text { Wind } \\
\text { direction } \\
\text { (Degree) }\end{array}$ & $\begin{array}{l}\text { Radiation } \\
\text { (W/m2) }\end{array}$ & $\begin{array}{l}\text { Soil } \\
\text { temp. } \\
\left({ }^{\circ} \mathrm{C}\right)\end{array}$ & $\begin{array}{c}\text { Soil } \\
\text { moisture } \\
(\%)\end{array}$ \\
\hline $3 / 07 / 12$ & 31 & 61 & 0.8 & 17 & 246 & 1166 & 30 & 34 \\
\hline $4 / 07 / 12$ & 27 & 71 & 0.2 & 11 & 235 & 352 & 29 & 28 \\
\hline $5 / 07 / 12$ & 32 & 94 & 6 & 28 & 264 & 1325 & 31 & 54 \\
\hline $6 / 07 / 12$ & 28 & 93 & 0.2 & 37 & 413 & 1448 & 30 & 28 \\
\hline $7 / 07 / 12$ & 29 & 94 & 0.2 & 32 & 218 & 186 & 30 & 29 \\
\hline $8 / 07 / 12$ & 29 & 89 & 0.0 & 27 & 367 & 1553 & 30 & 14 \\
\hline
\end{tabular}

\section{CONCLUSION}

With the use of this technique we can reduced water consumption. It can be set to lower and upper thresholds to maintain optimum soil moisture saturation and minimize plant wilting. It can contribute to deeper plat root growth, reduced soil runoff/leaching, less favorable conditions for insects and fungal disease. It is also possible to control the nutrition levels in their entirety thus, lower nutrition costs. No nutrition pollution is released into the environment because of the controlled system. Hence will have great saving of irrigation water, stronger, healthier plants and stable, high yields. Hence definitely will have improvement in biological fertility.

\section{ACKNOWLEDGMENT}

Special thanks to Dr. S. D. Lokhande (Principal Sinhgad College of Engineering Pune) \& Dr. A. D. Jadhav. (HOD E \& Tc.) giving precious guidance and information related to this work .

\section{Journal Papers:}

\section{REFERENCES}

[1] Integrated sensor suite installation manual

[2] P. Javadi Kia, A. Tabatabaee Far, M. Omid, R. Alimardani and L. Naderloo,” ,” Intelligent Control Based Fuzzy Logic for Automation of Greenhouse Irrigation System and Evaluation in Relation to Conventional Systems"in the World Applied Sciences Journal 6 (1): 16-23,2009.

[3] Hao sipeng Zhang Yangfei Li Xianyun Yuan Yue, The equivalent wind speed model in the wind farm dynamic analysis, Forth international conference on Electric Utility Deregulation and Power Technologies (DRPT),2011

[4] Cuihong Liu Wentao Ren Benhua Zhang Changyi Lv, The application of soil temperature measurement by LM35 temperature sensors, International conference on Electronic and Mechanical Engineering and Information Technology (EMEIT),2011

[5] Hao sipeng Zhang Yangfei Li Xianyun Yuan Yue Sch. Of power Electr. Eng., Nanjing Inst. Of Technol, Nanjing, China "Equivalent wind speed model in wind farm dyanamic analysis" $4{ }^{\text {th }}$ International Conference on Electric Utility Deregulation and Restructuring and Power Technologies (DRPT),2011

[6] Sulaiman, S. Manut, A. Nur Firdaus, A.R, Design, Fabrication and testing of Fringing Electric Field Soil Moisture sensor for wireless Precision Agriculture Applications, International Conference on Information and Multimedia Technology,2009,ICIMT’09

[7] Singh,N.Mohan,A. Dept. of Phys., Nehru Coll., Chhibramau "Determination of size and number density of water droplets by the measurement of intensity of scattered light" International Conference on Mathematical Methods in Electromagnetic Theory, 1998. MMET 98. 1998

[8] Jiachun Li Wentei Tu, An Irrigation Control System Based on C8051F and ARM, International Conference on Digital Manufacturing and Automation (ICDMA), 2010

[9] Valente, A. Boaventura Cunha, J. Couto, C., Soil moisture sensor with built-in fault-detection capabilities, Proceedings of the 24th Annual Conference of the IEEE Industrial Electronics Society, 1998. IECON '98.

[10] Sulaiman, S. Manut, A. Nur Firdaus, A.R, Design, Fabrication and Testing of Fringing Electric Field Soil Moisture Sensor for Wireless Precision Agriculture Applications, International Conference on Information and Multimedia Technology, 2009. ICIMT '09. 


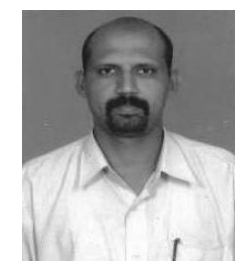

Vaibhav V. Dixit was born on July $31^{\text {st }} 1973$. He received his BE degree in the field of Electronics and Telecommunications Engineering in 1996 from Shivaji University, Kolhapur. He has completed ME in Electronics Engineering at SCOE, affiliated to University of Pune in 2007. He is working as Assistant Professor in the Department of E \&TC of Sinhgad College of Engineering Pune since 2002. His research interests are in Image Processing and Biomedical applications. He has 14 yrs of teaching experience. He has published one paper in International Journal and seven papers in International and National Conferences. Mr. Dixit is a life member of ISTE, New Delhi.

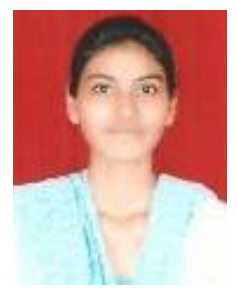

Pranita Anil Bhosale is a M.E. student in VLSI and Embedded system at the University of Pune (INDIA). Her birth palce is Pune itself and birth date is 29 th June 198 9. She has tak en bachelor of Engineering from Parvatibai Genba Moze College Of Engineering at Wagholi,Pune , Maharashtra . Bachelor of En gineering in Electronics and Telecommun ication, has taken on February 2010. Now she is doing Master of Engineering from Pune University at Sinhgad college of Engineering wadgaon budruk. Her research focuses on precision agriculture, soil conservation, crop irrigation scheduling and water quantity control for increasing water use efficiency. 